\title{
Diversidade genética entre acessos de espinheira-santa (Maytenus ilicifolia Mart. ex Reis.) coletados no estado do Rio Grande do Sul, Brasil
}

\author{
RIBEIRO, M.V. ${ }^{1}$; BIANCHI, V.J. ${ }^{1}$; RODRIGUES, I.C.S. ${ }^{1}$; MARIOT, M.P. ; BARBIERI, R.L. ${ }^{2}$; PETERS, J.A. ; BRAGA, \\ E.J.B. ${ }^{1}$ \\ 'Laboratório de Cultura de Tecidos de Plantas, Departamento de Botânica, Instituto de Biologia, Universidade \\ Federal de Pelotas, Campus Universitário, s/n., CEP: 96160-000, Capão do Leão-Brasil *marciavribeiro@ \\ hotmail.com ${ }^{2}$ Instituto Federal de Educação, Ciência e Tecnologia Sul-Rio-Grandense-Campus Pelotas Visconde \\ da Graça, Avenida Idelfonso Simões Lopes, 2791, CEP: 96060-290, Pelotas-Brasil ${ }^{3}$ Embrapa Clima Temperado, \\ BR 392, km 78, Caixa Postal 403, CEP 96010-971, Pelotas-Brasil
}

RESUMO: Maytenus ilicifolia Mart. ex Reis., popularmente conhecida como espinheira-santa, é espécie autóctone pertencente à família Celastraceae, usada para tratamento de úlceras gástricas e gastrites. Devido à importância medicinal, houve aumento no extrativismo das populações naturais, tornando-a uma espécie prioritária para a conservação, a fim de evitar a erosão genética. Buscou-se com este trabalho analisar a diversidade genética de 20 acessos de $M$. ilicifolia coletados em diferentes localidades no Rio Grande do Sul. Utilizando marcadores moleculares do tipo AFLP, foram testadas oito combinações de primers, que geraram 455 bandas eletroforéticas, $100 \%$ polimórficas. As combinações de primers E-ACC/M-CAA, E-ACG/M-CTA, E-ACG/M-CTC apresentaram o maior número de bandas eletroforéticas, 71 cada, totalizando $46,80 \%$ do polimorfismo total. Os valores de similaridade genética calculada pelo coeficiente simple matching foram utilizados para gerar o dendrograma de similaridade pelo método UPGMA. Foi obtido alto coeficiente de correlação cofenética $(r=0,94)$, demonstrando elevada representatividade dos dados de similaridade genética no dendrograma. Pela AMOVA verificou-se que $89,33 \%$ da diversidade total ocorreram entre indivíduos dentro das populações. A caracterização molecular de acessos de Maytenus ilicifolia por meio de AFLP foi eficiente para identificar diversidade genética. Através da análise de similaridade genética o banco de germoplasma poderia ser composto com os acessos que apresentaram menor similaridade e maior número de alelos, permitindo com que estes fornecessem ampla cobertura do genoma que compõem Maytenus ilicifolia. Os acessos que ficaram agrupados em mesmo clustere com número reduzido de alelos podem ser descartados deste banco. A diversidade genética intrapopulacional identificada por esse marcador foi muito maior do que aquela entre populações.

Palavras-chave: marcadores moleculares, similaridade genética, AFLP, AMOVA

\begin{abstract}
Genetic diversity of "espinheira-santa" (Maytenus ilicifolia Mart. ex Reis.) accessions collected in Rio Grande do Sul State, Brazil. Maytenus ilicifolia Mart. ex Reis., popularly known as "espinheira-santa", is an autochthonous species belonging to the Celastraceae family. This species is used to treat ulcers and gastritis. Due to its medicinal importance, the exploitation of natural populations has increased, making the conservation of this species essential to prevent genetic erosion. The aim of this work was to analyze the genetic diversity of $20 \mathrm{M}$. ilicifolia accessions collected in different localities of Rio Grande do Sul State. Using AFLP-type molecular markers, eight primer combinations were tested, producing 455 electrophoretic profiles, with $100 \%$ polymorphism. The primer combinations E-ACC/M-CAA, E-ACG/M-CTA and E-ACG/ M-CTC presented the largest number of electrophoretic profiles, 71 each, totaling $46.80 \%$ of the total polymorphism. The values of genetic similarity estimated by Simple Matching Coefficient were used to produce the dendrogram of similarity by the UPGMA method. A high cophenetic correlation coefficient $(r=0.94)$ was obtained, demonstrating high representativeness of the data of genetic similarity in the dendrogram. Using AMOVA, $89.33 \%$ of the total diversity were observed
\end{abstract}

Recebido para publicação em 17/10/2008

Aceito para publicação em 19/07/2010

Rev. Bras. PI. Med., Botucatu, v.12, n.4, p.443-451, 2010. 
among individuals from the same population. The molecular characterization of Maytenus ilicifolia accessions by AFLP allowed the identification of genetic diversity. The genetic similarity analysis indicated that the germplasm bank could be composed of the accessions presenting the lowest similarity and the largest numbers of alleles, providing a comprehensive coverage of Maytenus ilicifolia genome. The accessions that were grouped into one same cluster and with a reduced number of alleles could be disposed of this bank. The genetic diversity identified by this marker within populations was much greater than that between populations.

Key words: molecular markers, genetic similarity, AFLP, AMOVA

\section{INTRODUÇÃO}

O Brasil possui diversidade vegetal que proporciona posição de destaque em relação à diversidade de espécies nativas com potencial medicinal (Vieira, 1999). Dentre estas se destaca a espinheira-santa (Maytenus ilicifolia Mart. ex Reiss.), pertencente à família Celastraceae, com maior ocorrência nos estados do Paraná, Santa Catarina e Rio Grande do Sul (Mariot \& Barbieri, 2007).

Entre os metabólitos secundários que estão associados à ação farmacológica em M. ilicifolia, destacam-se os triterpenos, os taninos e os flavonóides (Di Stasi, 2004; Mariot \& Barbieri, 2007). Por isso, esta espécie é utilizada no tratamento de úlcera gástrica e gastrite, tendo os resultados comprovados por pesquisas coordenadas pelo CEME (Central de Medicamentos) do Ministério da Saúde (Carlini, 1988) e ainda por apresentar propriedades analgésicas, anti-sépticas e cicatrizantes (Almeida, 1993; Di Stasi, 2004).

Conforme Carvalho-Okano \& Leitão-Filho (2004), esta espécie foi descrita morfologicamente por Reissek (1861) e revisada por Carvalho-Okano (1992), e em trabalho realizado com uma população de Viamão (RS), Scheffer (2001) observou taxa estimada de cruzamento de 0,996 pelo método multiloco e 0,974 pela média dos locos individuais. Por sua vez Steenbock \& Reis (2004), através da avaliação de duas populações de Guarapuava (PR), observaram taxa de cruzamento pelo método multiloco de 0,729 e 0,954 e para a média de locos individuais de 0,680 e 0,913 , respectivamente. Esses dados estão representando principalmente eventos reprodutivos realizados com indivíduos não aparentados, portanto, com maior probabilidade de ocorrer altas taxas de fecundação cruzada (alogamia) (Perecin et al., 2004).

A exploração de plantas em populações naturais desta espécie, sem critérios de manejo adequados, pode acabar promovendo redução demográfica drástica das mesmas, bem como perda significativa de diversidade genética. Assim, faz-se necessário a geração de critérios técnico-científicos para o manejo sustentável dessas populações, os quais devem servir como fundamentação para a elaboração de planos de manejo e para a promoção de legislação adequada em relação à atividade de exploração (Steenbock \& Reis, 2004).

A forte ação antrópica a que a espinheirasanta vem sendo submetida e a carência de informações com relação à caracterização de germoplasma tem levado a perda de material vegetal e, por consequência, perda da diversidade genética (Mariot, 2005), que é uma medida de biodiversidade baseada na variação genética dentro de cada espécie, tanto entre populações geograficamente separadas como entre os indivíduos de uma dada população (Primack, 2006).

No sentido de contribuir com os estudos de caracterização e preservação da diversidade genética de espinheira-santa, a Embrapa Clima Temperado formou um Banco Ativo de Germoplasma (BAG), com acessos oriundos de vários locais do Rio Grande do Sul. Descritores morfológicos foram utilizados para caracterizar as plantas matrizes (Mariot et al., 2003) e as progênies presentes no BAG (Mariot et al., 2009).

Em função da importância ecológica e do alto grau de erosão genética, o desenvolvimento de técnicas de estudo de diversidade genética em espinheira-santa é de grande importância, pois podem auxiliar em programas de conservação, que envolvem a preservação, recuperação e manejo de matas, além de melhoramento genético (Stefenon et al., 2003).

Os estudos sobre a identificação e caracterização da diversidade em plantas concentramse em vários aspectos, desde características morfofenológicas, bioquímicas e até características em nível de DNA (Ferreira \& Grattapaglia, 1996; Oliveira et al., 2005).

Diversas técnicas de marcadores moleculares têm sido utilizadas para a análise da diversidade em várias espécies vegetais. Marcadores do tipo AFLP (Amplified Fragment Length Polymorphisms), que combinam o uso de enzimas de restrição e a técnica de PCR (Polymerase Chain Reaction), possuem caráter dominante e revelam altos níveis de polimorfismo com grande número de bandas, apresentado precisão em análises de germoplasma. Desta forma, a técnica de AFLP possui vantagens em relação a outras técnicas,

Rev. Bras. PI. Med., Botucatu, v.12, n.4, p.443-451, 2010. 
como Random Amplification of Polymorphic DNA(RAPD) e marcadores morfológicos, devido à possibilidade de identificar alto nível de polimorfismo e pela maior reprodutibilidade (Tang et al., 2003; Yang et al., 2005).

Diante do exposto, este trabalho foi desenvolvido com o objetivo de analisar a diversidade genética de 20 acessos de $M$. ilicifolia coletados em diferentes localidades no estado do Rio Grande do Sul.

\section{MATERIAL E MÉTODO}

Foram utilizados 20 genótipos de Maytenus ilicifolia Mart. ex Reis, caracterizados como acessos, identificados pelo professor, Dr. Márcio Paim Mariot, cujas exsicatas dos acessos encontram-se depositadas no Herbário da Embrapa Clima Temperado, Pelotas-RS. Os números dos diferentes acessos, os locais e datas de coleta estão descritos na Tabela 1. A análise molecular foi realizada a partir de folhas jovens que haviam sido armazenadas a $-80^{\circ} \mathrm{C}$, no Laboratório de Cultura de Tecidos de Plantas, do Departamento de Botânica, Instituto de Biologia da Universidade Federal de Pelotas-RS.

A extração de DNA foi realizada pelo método proposto por Doyle \& Doyle (1990), com algumas modificações, onde foram utilizadas $0,15 \mathrm{~g}$ de folhas jovens maceradas em nitrogênio líquido e adicionados $750 \mu \mathrm{L}$ de tampão de extração CTAB (2\%) e $\beta$ mercaptoetanol (1\%).

As amostras de DNA foram submetidas às etapas padrões de análise descrita para o Kit Invitrogen AFLP® Analysis System I. Para amplificação final foram utilizadas oito combinações de primers (MCAG/E-AGC; M-CAG/E-AGG; M-CTA/E-AAC; M-CTA/ E-ACG; M-CTA/E-ACA; M-CAA/E-ACC; M-CTC/E$A C G)$.

O produto final da PCR $(5,0 \mu \mathrm{L}$ de cada amostra) foi vertido em gel desnaturante de poliacrilamida $6 \%$, sendo utilizado tampão TBE $1 \mathrm{X}$, para a eletroforese, que foi conduzida em cuba vertical TVS 1400 e fonte CONSORT E-832, por duas horas, a 1250V. A revelação do gel foi realizada com uso de nitrato de prata, conforme protocolo descrito por Bassam et al. (1991).

Os fragmentos amplificados foram mensurados para presença (1) ou ausência (0) de bandas em cada perfil eletroforético na comparação dos acessos. A partir destes dados foi montada matriz binária com os dados dos diferentes acessos. Baseado no estudo realizado por Bonin et al. (2007), optou-se por realizar a análise da similaridade genética utilizando o coeficiente simple matching (Sokal \& Michener, 1958) e para o agrupamento utilizou-se o método de ligação média não-ponderada (Unweighted Pair-Group Method with Arthmetic Average - UPGMA), por meio do software NTSYS-pc (Rholf, 2000). A partir da matriz de similaridade, foi computada a estabilidade dos agrupamentos pela análise de Bootstrap com 1000 replicações utilizando o programa computacional Winboot (Yap \& Nelson, 1996) e a análise de coordenadas principais proposta por Gower (1966).

Para a análise da variância dos dados moleculares (AMOVA) com o software Genes (Cruz, 2001), os acessos foram agrupados em populações, em função dos municípios onde foram coletados. Pelo fato de ter sido coletado somente um acesso no município de Pelotas (85), este foi incluso, para análise, junto à população de Candiota (população três) devido à proximidade dos municípios.

\section{RESULTADO E DISCUSSÃO}

Grande número de bandas AFLP foi obtido para cada uma das oito combinações de primers, produzindo um total de 455 bandas eletroforéticas,

TABELA1. Origem dos acessos de Maytenus ilicifolia utilizadas para análise molecular, coletados em seis municípios do estado do Rio Grande do Sul.

\begin{tabular}{ccccc}
\hline Acesso & Município de coleta & Data coleta & $\begin{array}{c}\text { Número da } \\
\text { exsicata }\end{array}$ & População* $^{*}$ \\
\hline $1,2,3,6$ e 7 & Encruzilhada do Sul & $23 / 12 / 2002$ & $1,2,3,6$ e 7 & 01 \\
44,47 e 54 & Pir atini & $28 / 12 / 2002$ & $44,47 \mathrm{e} 54$ & 02 \\
51 & Pir atini & $23 / 12 / 2002$ & 51 & \\
$64,66,70,74$ e 75 & Candiota & $12 / 12 / 2002$ & $64,66,70,74$ e 75 & 03 \\
85 & Pelotas & $10 / 12 / 2002$ & 85 & \\
99 e 101 & Caxias do Sul & $09 / 01 / 2003$ & 99 e 101 & 04 \\
103 & Esmeralda & $09 / 01 / 2003$ & 103 & 05 \\
108 e 111 & Esmeralda & $11 / 01 / 2003$ & 108 e 111 & \\
\hline
\end{tabular}

\footnotetext{
${ }^{*}$ Grupos utilizados para AMOVA.
} 
sendo $100 \%$ polimórficas (Tabela 2). As combinações dos primers M-CTA/E-ACG, M-CAA/E-ACC e M-CTC/ E-ACG foram as que amplificaram o maior número de bandas, 71 cada, contribuindo com $46,80 \%$ do total de polimorfismos. Esta alta taxa de polimorfismo detectado é justificada pelo fato desta técnica explorar simultaneamente o polimorfismo de presença e ausência de sítios de restrição (Wünsch \& Hormaza, 2002), associado à ocorrência ou não de amplificação a partir de seqüências arbitrárias, conseguindo assim flexibilidade significativa na obtenção de polimorfismos (Ferreira \& Grattapaglia, 1996).

A ausência de bandas monomórficas evidenciou a grande diversidade genética presente nos acessos de M. ilicifolia estudados. Altas taxas de polimorfismo, similares às identificadas no presente trabalho, foram detectadas pela técnica AFLP por vários autores. Odat et al. (2004), estudando a diversidade genética de Ranunculus acris, observaram a presença de $79,5 \%$ de polimorfismo; já Monte-Corvo et al. (2000), trabalhando com cultivares de Pyrus, obtiveram $87 \%$ de bandas polimórficas. Por sua vez, Goulão et al. (2001) observaram 57,2\% de polimorfismo em análise da similaridade genética entre cultivares de Malus.

$\mathrm{Na}$ análise dos géis, as bandas que apresentaram tamanho inferior a 100pb não foram registradas devido à inconsistência de amplificação e revelação. Por outro lado, dependendo da combinação de primers utilizada, as bandas de maior tamanho apresentaram variação entre 400pb e 600pb e o número de bandas amplificadas com cada combinação de primers variaram de 38 a 71, com valor médio de 57 polimórficos (Tabela 2), confirmando a alta eficiência da técnica (Figura 1).
A relação genética entre os 20 acessos foi baseada nos dados de similaridade e calculada pelo coeficiente simple matching (Sokal \& Michener, 1958), estando representada no dendrograma da Figura 2. Os dados do dendrograma foram utilizados para gerar uma matriz cofenética que quando comparada à matriz de similaridade, apresentou um coeficiente de correlação alto $(r=0,94)$, indicando boa correspondência dos dados de agrupamento em relação à similaridade original.

Exceto os acessos 103, 108 e 111, coletados no município de Esmeralda, que ficaram agrupados juntos (Figura 2), de maneira geral houve ampla dispersão dos acessos avaliados, ou seja, aqueles coletados em localidades próximas foram agrupados relativamente distantes, indicando que a diversidade genética desta espécie não esta associada diretamente à distância geográfica entre os acessos, mas está relacionada a forças evolutivas, tais como mutação, recombinação, migração, deriva genética e seleção, que provocam mudanças nas freqüências dos genes (alelos) nas populações (Perecin et al., 2004), bem como a história de vida da espécie, envolvendo status taxonômico, distribuição geográfica, sistema de acasalamento, tipo de dispersão de sementes e estágio sucessional (Hamrick \& Godt, 1989).

A interferência do homem também é um dos fatores que até o presente podem ajudar a explicar a alta diversidade detectada entre os indivíduos avaliados, devido à ação de superexploração dos ambientes de ocorrência natural. Segundo dados da Associação Brasileira da Indústria de Fitoterápicos (ABIFITO), M. ilicifolia é a quarta espécie medicinal mais comercializada no país (Mariot, 2005) e a fragmentação das populações podem estar levando

TABELA 2. Dados de polimorfismo obtidos na análise de 20 acessos de Maytenus ilicifolia, com diferentes combinações de primers AFLP.

\begin{tabular}{cccc}
\hline Primers & Número de bandas & $\%$ de BP & \% de PP/PT \\
\hline M-CAG/E-AGC & 39 & 100 & 8,57 \\
M-CAG/E-AGG & 45 & 100 & 9,90 \\
M-CTA/E-AAC & 38 & 100 & 8,35 \\
M-CTA/E-ACG & 71 & 100 & 15,60 \\
M-CTA/E-ACA & 61 & 100 & 13,41 \\
M-CAA/E-ACC & 71 & 100 & 15,60 \\
M-CTC/E-ACG & 71 & 100 & 15,60 \\
M-CTC/E-ACT & 59 & 100 & 12,97 \\
\hline Média & 57 & 100 & \\
\hline Total & 455 & & 100 \\
\hline
\end{tabular}

* PP: porcentagem de bandas polimórficas; *^PP/PT: relação do polimorfismo por combinação de primers em relação ao polimorfismo total. 

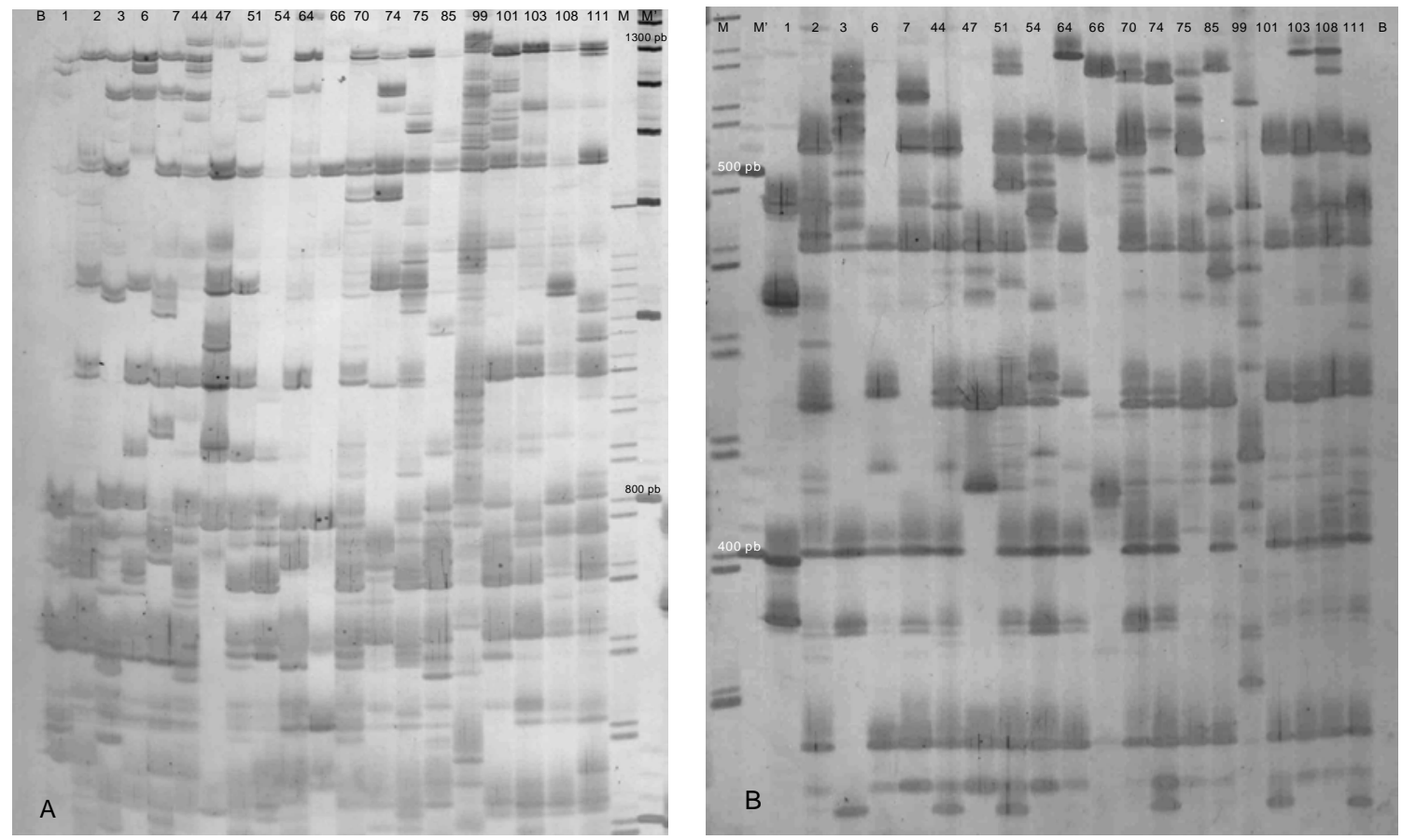

FIGURA 1. Perfil eletroforético de 20 acessos de Maytenus ilicifolia, gerados pela combinação de primers AFLP EACC/M-CAA (A) e E-ACG/M-CTA (B). B - Branco; M - marcador molecular 25pb; M' - 100pb (Life Tecnologies, Inc.).

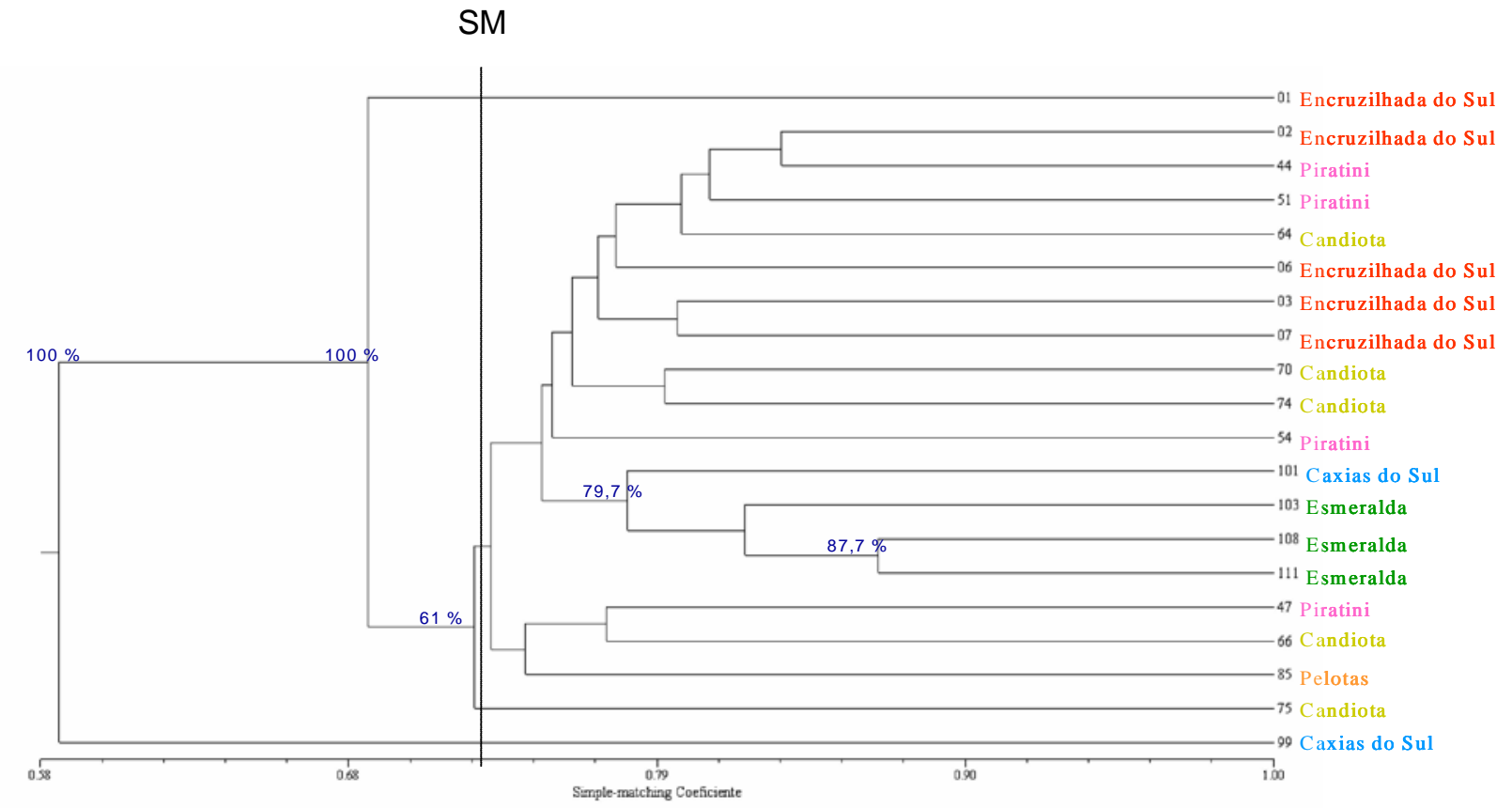

FIGURA 2. Dendrograma de similaridade genética obtido pelo método UPGMA, baseado em polimorfismos AFLP de 20 acessos de Maytenus ilicifolia. SM = similaridade genética média. Coeficiente de correlação $r=0,94$.

ao isolamento das mesmas, sendo um dos motivos relacionados à obtenção de dados de diversidade comgrande divergência. Por outro lado, os efeitos de fluxo gênico provocado pela fauna silvestre ou pelo homem tendem a homogeneizar as populações, reduzindo divergências, sendo assim, estudos relativos à ecologia de polinização e de dispersão de sementes, bem como relativos à demografia da espécie se fazem necessários, a fim de elucidar melhor os condicionantes do fluxo gênico e a distância de conectividade entre as populações (Perecin et al., 2004). A partir da existência dessa conectividade, pode ser possível o manejo de populações menores da espécie, na medida em que haja um elevado fluxo 
gênico, possibilitando a manutenção da diversidade genética das mesmas (Steenbock \& Reis, 2004).

Os acessos 108 e 111, coletados em Esmeralda, apresentaram a maior similaridade genética entre si $(0,83)$ com valores de bootstrap de $87,7 \%$. Mesmo a análise AFLP ter produzido um significativo número de polimorfismos, a confiabilidade dos agrupamentos, indicada pela análise de bootstrap, foi pouco significativa, exceto para os acessos 99 e 01, provenientes de Caxias do Sul e Encruzilhada do Sul, respectivamente, que agruparam de forma similar pelos métodos UPGMA e PCA (Figuras 2 e 3), apresentando valores de bootstrap de $100 \%$.

O agrupamento do acesso 101 de Caxias do Sul, com os acessos de Esmeralda apresentou valor de bootstrap de $79,9 \%$, indicando que o primeiro acesso compartilha um maior número de bandas com acessos de Esmeralda. A grande distância genética verificada entre os acessos coletados em Caxias do Sul pode ser resultado da introdução de plantas vindas de Esmeralda, no caso do acesso 101 (Figura 2).

Pela análise de variância molecular (AMOVA) baseada nos 455 polimorfismos AFLP, o valor $F_{\text {st }}$ estimado foi altamente significativo $\left(F_{s t}=0,10\right)$, revelando que $10,67 \%$ da variação genética total ocorrem entre populações e $89,33 \%$ entre indivíduos dentro da mesma população (Tabela 3).
Em outras espécies, Odat et al. (2004) observaram alta taxa de variabilidade dentro da população de Ranunculus acris L. (89,03\%), em relação aquela entre populações $(10,97 \%)$, sugerindo que os indivíduos presentes dentro da população apresentam grande proporção de locide alta variação alélica. De forma similar, Freitas et al. (2005) demonstraram que $16,2 \%$ da variabilidade genética de Myracrodruon urundeuva, popularmente conhecida como aroeira, se encontrava entre as populações e 83,8\% dentro da população.

A análise de populações naturais de $M$. ilicifolia no estado do Paraná, avaliada por meio de marcadores RADP, revelou que a variabilidade genética entre indivíduos da mesma população foi de $85 \%$, entre populações foi de 15\% (Bittencourt, 2000). Resultados similares foram obtidos por Perecin et al. (2004) em populações de M. ilicifolia e M. aquifolium avaliadas por meio de marcadores isoenzimáticos. Estes resultados confirmam, juntamente com os do presente trabalho, que independente do marcador genético utilizado nas análises de Maytenus spp., há maior diversidade entre os indivíduos da mesma população, o qual também é observado em outros gêneros de plantas.

Loveless \& Hamrick (1984) observaram que em populações naturais de plantas são preservadas

TABELA 3. Análise da variância molecular (AMOVA) de 20 acessos divididos em cinco populações de Maytenus ilicifolia, coletados no estado do Rio Grande do Sul. GL = graus de liberdade; $\mathrm{SQ}=$ soma dos quadrados; $\mathrm{QM}=$ quadrados médios.

\begin{tabular}{cccccc}
\hline Fonte de Variação & GL & SQ & QM & $\begin{array}{c}\text { Componente de } \\
\text { variância }\end{array}$ & Total (\%) \\
\hline Entre populações & 4 & 330,283 & 82,571 & 6,744 & $10,674^{\star \star}$ \\
Dentro da população & 15 & 846,567 & 56,438 & 56,438 & $89,326^{* \star}$ \\
\hline Total & 19 & 1176,85 & 61,939 & 63,182 & 100,0 \\
\hline
\end{tabular}

$\mathrm{F}_{\text {st }}=0,10$ (estimativa da diferença entre heterozigosidades esperada e total das populações). ${ }^{* \star}$ significativo ao nível de $1 \%$ de probabilidade de erro.

grandes quantidades de variabilidade dentro das populações e a distribuição da variabilidade genética natural é influenciada por fatores como modo de reprodução das espécies, sistema de cruzamento, tamanho efetivo da população, distribuição geográfica e fluxo gênico. Espécies tipicamente alógamas apresentaram alta variação genética intrapopulacional em detrimento àquela interpopulacional, sendo que a divergência dentro de populações é inversamente proporcional à quantidade de fluxo gênico, ou seja, quanto maior esse fluxo menor a divergência intrapopulacional. A distribuição espacial não aleatória da diversidade genética em indivíduos dentro de populações naturais de plantas pode influenciar de maneira significativa os processos evolucionários e ecológicos, sendo que esta variação genética poderá ter conseqüências diretas sobre os processos de diferenciação que levam à especiação, pois a estruturação em microhabitats pode promover por meio de seleção e deriva a formação local de novos genótipos (Perecin et al., 2004).

Os agrupamentos dos acessos obtidos pelo 
método de coordenadas principais (PCA) (Figura 3) também originou quatro agrupamentos, porém, revelando algumas diferenças em relação ao agrupamento obtido pelo método UPGMA.

Como pode ser observado no dendrograma (Figura 2), através da similaridade genética média, dentre os quatro grupos formados, o maior é representado pelos acessos 02, 03, 06 e 07 de Encruzilhada do Sul, 44, 51 e 54 de Piratini, 64, 70, 74 e 75 de Candiota, 85 de Pelotas, 101 de Caxias do Sul e 103, 108, 111 de Esmeralda. Os acessos 47 e 66, de Piratini (07) e Candiota (11), respectivamente, ficaram no mesmo grupo principal quando analisados pelo método UPGMA, porém ficaram agrupados separadamente pelo PCA.

O acesso 75 Candiota (14) ficou posicionado no grupo principal quando analisados pelo método PCA, diferentemente ao observado pelo método UPGMA, enquanto que os acessos 99 de Caxias do sul (16) e 01 de Encruzilhada do Sul (01), pelos dois métodos de análise, formaram dois grupos idividualmente separados e isolados de sua população original, sendo estes, os que mais contribuíram para a variação total. Sendo assim, este tipo de representação gráfica nos permite uma visão da distribuição geral das populações, podendo-se observar que os grupos formados foram bem distintos aos da população original.

Essas diferenças observadas na forma de agrupamento com cada método podem ser explicadas em função de que o método PCA proporciona otimização das distâncias representadas multidimensionalmente, não havendo variação na maneira de agrupamento, enquanto que os métodos de agrupamento baseado em matrizes de similaridade podem originar diferenças em função do coeficiente de similaridade utilizado e do próprio método de agrupamento (Carvalho et al., 2009). Mesmo assim, verificou-se que o acesso 01 de Encruzilhada do Sul (01) foi um dos que ficou mais distante de sua população de origem. Corroborando com este resultado, Mariot \& Barbieri (2010), através da análise de dados morfológicos, observou que este mesmo acesso também ficou em um grupo totalmente isolado dos demais acessos.

No presente trabalho foi possível demonstrar a eficiência da técnica AFLP em identificar a diversidade nos acessos de $M$. ilicifolia, a qual deve ser mantida a fim de evitar risco de erosão genética, pois a manutenção desta espécie in situ, através de unidades de conservação ou manejo sustentável de populações naturais, é de extrema importância. De acordo com Perecin et al. (2004), o contato entre comunidades inteiras de populações de plantas com as comunidades originais é necessário para manter as interações ecológicas de que necessitam e continuar os processos evolutivos naturais, adaptando-se às mudanças climáticas em curso, aos estresses a as pressões a que são submetidas.

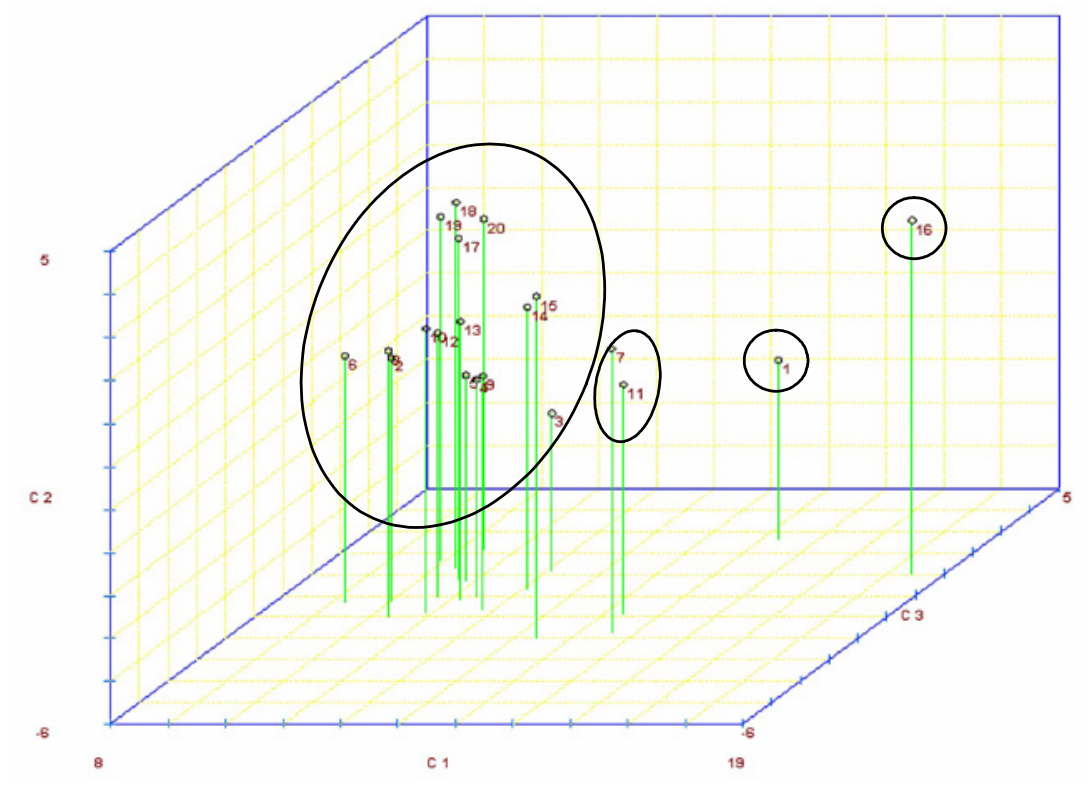

FIGURA 3. Associações entre 20 acessos de Maytenus ilicifolia, obtidos pela análise de coordenada principal dos coeficientes de similaridade simple machting calculados de 455 bandas AFLP geradas por oito combinações de primers. Os acessos 1(01), 2 (02), 3 (03), 4 (06), 5 (07), correspondem à população de Encruzilhada do Sul; 6 (44), 7 (47), 8 (51), 9 (54) a população de Piratini; 10 (64), 11 (66), 12 (70), 13 (74), 14 (75) e 15 (85) a população de Candiota e Pelotas; 16 (99), 17 (101) a população de Caxias do Sul; 18 (103), 19 (108), 20 (101) a população de Esmeralda. * Os círculos demonstram a forma de agrupamento dos acessos. 


\section{CONCLUSÃO}

Com as análises realizadas no presente trabalho é possível concluir que:

- em populações de M. ilicifolia do RS existe maior diversidade genética intrapopulacional do que interpopulacional;

- os marcadores AFLP permitem obter estimativas de diversidade genética de $M$. ilicifolia similares aos verificados com outros métodos de avaliação em espécies de Maytenus;

- devido à rapidez para a obtenção de um grande número de polimorfismo, marcadores moleculares do tipo AFLP representam uma ferramenta importante para auxiliar na composição de bancos de germoplasma, na forma de sementes e coleções vivas, possibilitando selecionar acessos que apresentem menor similaridade e maior número de alelos possíveis.

\section{REFERÊNCIA}

ALMEIDA, E.R. Plantas medicinais brasileiras. São Paulo: Hemus, 1993. 341p.

BASSAM, B.J. et al. Fast and sensitive silver staining of DNA in polyacrylamide gels. Analytical Biochemistry, v.196, p.80-3, 1991.

BITTENCOURT, J.V.M. Variabilidade genética em populações naturais de Maytenus ilicifolia por meio de marcadores RAPD. 2000. 58p. Dissertação (Mestrado Área de Concentração em Agronomia) - Departamento de Botânica, Universidade Federal do Paraná, Paraná. BONIN, A. et al. Statistical analysis of amplified fragment length polymorphism data: a toolbox for molecular ecologists and evolutionists. Molecular Ecology, v.16, p.3737-58, 2007.

CARLINI, E.A. (Coord.). Estudo da ação antiúlcera gástrica de plantas brasileiras: Maytenus ilicifolia (espinheira-santa) e outras. Brasília: CEME/AFIP, 1988. 87p.

CARVALHO, M.F. et al. Aplicação da análise multivariada em avaliações de divergência genética através de marcadores moleculares dominantes em plantas medicinais. Revista Brasileira de Plantas Medicinais, v.11, n.3, p.339-46, 2009.

CARVALHO-OKANO, R.M. Estudos taxonômicos do gênero Maytenus Mol. emend. Mol. (CELASTRACEAE) do Brasil extra-amazônico. 1992. 252p. Tese (Doutorado - Área de Concentração em Biologia Vegetal) - Departamento de Biologia Vegetal, Universidade Estadual de Campinas, Campinas.

CARVALHO-OKANO, R.M.; LEITÃO-FILHO, H. O gênero Maytenus Mol. Emend. Mol. (Celastraceae) no Brasil extra-amazônico. In: REIS, M.S.; SILVA, S.R. (Eds.). Plantas medicinais e aromáticas - Espinheira-Santa. Brasília: Editora IBAMA, 2004, p.11-21.

CRUZ, C.D. Programa genes: aplicativo computacional em genética e estatística. Viçosa: Editora UFV, 2001. $648 p$.

Di STASI, L.C. Aspectos químicos e farmacológicos da espinheira-santa: uma análise da utilização dos dados. In: REIS, M.S.; SILVA, S.R. (Eds.). Plantas medicinais e aromáticas: Espinheira-Santa. Brasília: Editora IBAMA, 2004. p.67-2.

DOYLE, J.J.; DOYLE, J.L. Isolation of plant DNA from fresh tissue. Focus, v.12, p.13-5, 1990.

FERREIRA, M.E.F.; GRATTAPAGLIA, D. Introdução ao uso de marcadores moleculares em análise genética. Brasília: Embrapa, 1996. 220p.

FREITAS, M.L.M. et al. Variabilidade genética intrapopulacional em Myracrodruon urundeuva Fr. All. por marcador AFLP. Scientia Forestalis, n.68, p.21-8, 2005. GOULÃO, L. et al. Comparaing RAPD and AFLPTM analysis in discrimination and estimation of genetic similarities among apple (Malus domestica Borkh.) cultivars. Euphytica, v.119, p.259-70, 2001.

GOWER, J.C. Some distance properties of latent root and vector methods used in multivariate analysis. Biometrika, v.53, p.325-38, 1966.

HAMRICK, J.L.; GODT, M.J.W. Allozyme diversity in plant species. In: BRONW, A.H.D. et al. Plant population genetics, breeding and genetic resources. Massachusetts: Sinauer Associates, 1989. p.43-3.

LOVELESS, M.D.; HAMRICK, J.L. Ecological determinants of genetic structure in plant populations. Annual Review of Ecology and Systematics, v.15, p.655, 1984.

MARIOT, M.P. Recursos genéticos de Espinheira-Santa (Maytenus ilicifolia e Maytenus aquifolium) no Rio Grande do Sul. 2005. 125p. Tese (Doutorado - Área de Concentração em Fitomelhoramento) - Departamento de Fitotecnia, Universidade Federal de Pelotas, Pelotas. MARIOT, M.P.; BARBIERI, R.L.; SINIGAGLIA, C. Dissimilaridade entre genótipos de Maytenus ilicifolia (espinheira-santa) de uma população do Rio Grande do Sul. In: CONGRESSO BRASILEIRO DE MELHORAMENTO DE PLANTAS, 2., 2003, Anais... Porto Seguro: Sociedade Brasileira de Melhoramento de Plantas, 2003.

MARIOT, M.P.; BARBIERI, R.L. Metabólitos secundários e propriedades medicinais da espinheira-santa (Maytenus ilicifolia Mart. ex Reiss. e Maytenus aquifolium Mart.). Revista Brasileira de Plantas Medicinais, v.9, n.3, p.89-9, 2007.

MARIOT, M.P.; BARBIERI, R.L. Divergência genética entre acessos de espinheira-santa (Maytenus ilicifolia Mart. ex Reiss. e Maytenus aquifolium Mart.) com base em caracteres morfológicos e fisiológicos. Revista Brasileira de Plantas Medicinais, v.12, n.3, p.243-49, 2010.

MARIOT, M.P. et al. Variabilidade genética para caracteres morfológicos e fisiológicos em espinheira-santa (Maytenus ilicifolia (Schrad.) Planch. e M. aquifolium Mart.). Revista Brasileira de Plantas Medicinais, v.11, n.3, p.310-6, 2009.

MONTE-CORVO, L. et al. Assessment of genetic relationships among Pyrus species and cultivars using AFLP and RAPD markers. Genetic Resources and Crop Evalution, v.47, p.257-65, 2000.

ODAT, N. et al. Genetic diversity of Ranunculus acris L. (Ranunculaceae) populations in relation to species diversity and habitat type in grassland communities. Molecular Ecology, v.13, p.1251-7, 2004.

OLIVEIRA, P.R.D. et al. Análise da diversidade genética por AFLP e identificação de marcadores associados à 
resistência em videiras. Revista Brasileira Fruticultura, v.27, n.3, p.454-7, 2005.

PERECIN, M.B. et al. Variabilidade isoenzimática em populações naturais de espinheira-santa Maytenus aquifolia Mart. e Maytenus ilicifolia Mart. ex Reiss. e suas aplicações para o manejo e conservação. Revista Brasileira de Plantas Medicinais, v.4, p.80-90, 2002. PERECIN, M.B.; STEENBOCK, W.; REISS, M.S. Genética de populações de espinheira-santa. In: REIS, M.S.; SILVA, S.R. (Eds.). Plantas medicinais e aromáticas: Espinheira-Santa. Brasília: Editora IBAMA, 2004. p.11544.

PRIMACK, R. Essentials of conservation biology. 4.ed. Massachusetts: Sinauer Associates, 2006. 585p. REISSEK, S. Celastrine, Ilicini, Rhamneae. In: MARTIUS, C.F.P., EICHLER, A.G. (Eds.). Flora Brasiliensis, v.11, n.1, p.1-30, 1861. Disponível em: <http://florabrasiliensis. cria.org.br/opus>. Acesso em: 20 de mar. 2006.

RHOLF, F. Numerical taxonomy and multivariate analysis system: version 2.10. New York: Exeter Software, 2000. 98p.

SCHEFFER, M.C. Sistema de cruzamento e variação genética entre populações e progênies de espinheirasanta. 2001. 104p. Tese (Doutorado - Área de Concentração em Silvicultura) - Departamento de Botânica, Universidade Federal do Paraná, Curitiba.

SOKAL R.R.; MICHENER, C.D. et al. A statistical method for evaluating systematic relationships. Science Bulletin, v.38, p.1409-38, 1958.

STEFENON, V.M. et al. Padronização de protocolo AFLP e sua capacidade informativa para análise da diversidade genética em Araucária angustifólia. Scientia Florestalis, n.64, p.163-71, 2003.

STEENBOCK, W.; REIS, M.S. Manejo de populações naturais de Espinheira Santa. In: REIS, M.S.; SILVA, S.R. (Orgs.). Plantas medicinais e aromáticas: Espinheira Santa. Brasília: Editora IBAMA, 2004. v.1, p.145-61.

TANG, T. et al. Genetic diversity of Hibiscus tiliaceus (Malvaceae) in China assessed using AFLP markers. Annuals of Botany, v.92, p.409-14, 2003.

VIEIRA, R.F. Conservation of medicinal and aromatic plants in Brasil. In: JANICK, J. (Ed.) Perspectives on new crops and new uses. Alexandria: ASHS Press, 1999. p.152-9.

WÜNSCH, A.; HORMAZA, J.I. Cultivar identification and genetic fingerprinting of temperate fruit tree species using DNA markers. Euphytica, v.125, p.59-67, 2002.

YANG, C. et al. Establishment of AFLP technique and assessment of primer combinations for mei flower. Plant Molecular Biology Reporter, v.23, p.79-80, 2005.

YAP, I.V.; NELSON, R.J. Winboot: a program for performing bootstrap analysis of binary data to determine the confidence limits of UPGMA-based dendrograms. Manila: IRRI, 1996. 22p. 